\title{
Short-term effects of gaseous air pollutants on outpatient visits for respiratory diseases: a case-crossover study in Baotou, China
}

\author{
Hao-Yu Gao ${ }^{1}$ Xiao-Ling Liü ${ }^{2}$ Ya-Ke Lu ${ }^{1}$ Yu-Hong Liu ${ }^{1} \cdot$ Li-Kun Hu$^{1} \cdot$ Yan-Ling $\mathrm{Li}^{1} \cdot$ Xiao-Dong Feng ${ }^{2} \cdot$ Yu-Xiang Yan ${ }^{1}$
}

Received: 29 September 2021 / Accepted: 21 February 2022 / Published online: 27 February 2022

(c) The Author(s), under exclusive licence to Springer-Verlag GmbH Germany, part of Springer Nature 2022, corrected publication 2022

\begin{abstract}
Air pollution is a major public health problem throughout the world. Although there have been several studies in this field, most of them have focused on particulate matter and only covered a few key cities. This study aimed to assess a potential association between exposure to gaseous air pollutants and outpatient visits for respiratory diseases in Baotou, China. Daily outpatient visits for respiratory diseases and daily averages of air pollutants and meteorological parameters from 2015 to 2020 were obtained. Time-stratified case-crossover design and restricted cubic splines were used to perform the analyses. Stratified analyses were performed in different hospital departments and districts. Significant association between the concentrations of air pollutants and outpatient visits for respiratory diseases was observed. The odds ratios of outpatient visits for respiratory diseases associated with per $10 \mu \mathrm{g} / \mathrm{m}^{3}$ increases in concentrations of $\mathrm{NO}_{2}$ and $\mathrm{SO}_{2}$, and per $10 \mathrm{mg} / \mathrm{m}^{3}$ increases in concentrations of CO were 1.033 (95\% CI: 1.018 to 1.049), 0.965 (95\% CI: 0.954 to 0.976), and 1.038 (95\% CI: 1.006 to 1.071), respectively. Short-term exposure to $\mathrm{NO}_{2}, \mathrm{SO}_{2}$, and $\mathrm{CO}$ was positively associated with outpatient visits for respiratory diseases, with stronger effects among children. The relationship between $\mathrm{O}_{3}$ and respiratory diseases varied at different concentrations.
\end{abstract}

Keywords Air pollutants · Environmental exposure $\cdot$ Respiratory diseases · Case-crossover design · Daily outpatient visits · China

\section{Introduction}

Ambient air pollution has been one of the most important public health concerns around the world (Cohen et al. 2017). In October 2013, the International Agency for Research on Cancer (IARC) classified outdoor air pollution as carcinogenic to humans (Loomis et al. 2013). Contributing to 3.7 million deaths worldwide annually, air pollution has been identified as the worldwide largest single environmental

Responsible Editor: Lotfi Aleya.

Hao-Yu Gao and Xiao-Ling Liu contributed equally to this study.

Yu-Xiang Yan

yanyxepi@ccmu.edu.cn

1 Department of Epidemiology and Biostatistics, School of Public Health, Capital Medical University, No. 10 Xitoutiao, You'anmenWai, Fengtai District, Beijing 100069, China

2 Baotou Center for Disease Control and Prevention, Baotou, Inner Mongolia 014030, China health risks (Amann et al. 2020; Nwanaji-Enwerem et al. 2016). Ambient air pollutants include gaseous air pollutants and particulate matter. At present, the correlation between particulate matter and human health has been widely studied, which suggests that gaseous air pollutants are also closely associated with human health (Katsouyanni et al. 1997). In recent years, as a country embarking on urbanization and industrialization, China has been struggling immensely with severe air pollution. "Brief Introduction of National Ecological Environment Quality in 2019" pointed out that among 337 prefecture-level cities in China, the proportion of air quality exceeding the standard is as high as 53.4\% (China 2020).

Respiratory diseases are diseases of the airways and other structures of the lung, among which chronic respiratory diseases are the leading causes of morbidity and mortality worldwide (Soriano et al. 2020). The respiratory system is exposed to the external environment directly, making it more susceptible to the effects and influences of the surrounding environment. Subsequently, air pollution has been widely acknowledged as a major influence and exacerbating factor in various respiratory diseases (Mokoena et al. 2019). 
Despite the continuous effort and significant improvements in ambient air quality over the past decade, respiratory diseases in China remain increasingly serious (Bao et al. 2020).

Recently, research on the association between air pollution and respiratory diseases has received increased attention. But these studies were mainly focused on particulate matter, research on gaseous air pollutants has been relatively sparse (Chen et al. 2021; Zhang et al. 2020). In addition, previous research mainly covered a few key cities or urban agglomerations (Chang et al. 2020; Phung et al. 2016; Zhang et al. 2019a). As an important industrial city in Inner Mongolia, Baotou has been experiencing serious air pollution over the past few years. Nevertheless, limited studies have been conducted to evaluate the relationships between exposure to air pollutants and outpatient visits for respiratory diseases in this city. Given the above, more related studies are needed to be initiated there.

The outpatient services are open to all diseases with various severities and are not restricted by bed availability. Thus, outpatient visits could better reflect the medical need of most people compared to emergency department visits and hospitalizations (Wang et al. 2018). The aim of this study was to assess the potential associations between exposure to gaseous air pollutants and outpatient visits for respiratory diseases in Baotou.

\section{Materials and methods}

\section{Study setting}

Baotou is a city in the central and western parts of Inner Mongolia. As an important industrial base in China, Baotou's pillar industries are manufactured of steel and smelting of nonferrous metals. Baotou has a middle temperate semiarid continental monsoon climate, leading to lack of precipitation and seasonal temperature fluctuations. Compared with most of the cities in northern China, Baotou has a longer heating period and relies on coal-fired heating. Through the adoption of a series of control measures, the air quality in Baotou has gradually improved over recent years. However, the improvement in air quality is insignificant, and air pollution problem in Baotou is still fraught.

\section{Data collections}

\section{Daily records of outpatient visits for respiratory diseases}

Daily records of outpatient visits were collected from two general hospitals and two community hospitals in Baotou from January 1, 2015, to December 31, 2020. Four hospitals were selected from Donghe District and Qingshan District of Baotou. These two districts were defined as seriously polluted area and lightly polluted area according to the Ambient Air Quality Index, respectively. Total outpatient visits in all of these four hospitals had not reached saturation. Respiratory diseases were included in this study and were coded according to the International Classification of Diseases, Tenth Revision (ICD-10), chapter X: Diseases of respiratory system (J00-J99). Information about patients such as consultation date, hospital, and outpatient department was recorded.

\section{Air pollutants and meteorological data}

Nitrogen dioxide $\left(\mathrm{NO}_{2}\right)$, sulfur dioxide $\left(\mathrm{SO}_{2}\right)$, carbon monoxide $(\mathrm{CO})$, ozone $\left(\mathrm{O}_{3}\right)$, inhalable particulate matter $\left(\mathrm{PM}_{10}\right)$, and fine particulate matter $\left(\mathrm{PM}_{2.5}\right)$ measurements in Baotou during January 1, 2015, to December 31, 2020, were retrieved from Baotou Environmental Monitoring Station. The Environmental Monitoring Station comprised eight monitoring sites in six different districts, and air pollutants data from two monitoring sites in Donghe District and two monitoring sites in Qingshan District was included in our study. For each district, we obtained daily mean concentrations of $\mathrm{NO}_{2}, \mathrm{SO}_{2}$, and $\mathrm{CO}$ and maximum daily 8-h mean concentrations of $\mathrm{O}_{3}$. Meteorological data, including mean temperature, relative humidity, atmospheric pressure, and wind speed, were obtained from Baotou Meteorological Bureau.

\section{Study design}

A time-stratified case-crossover design was used to assess the acute effects of exposure to gaseous air pollutants on outpatient visits for respiratory diseases. With each case acting as its own control, case-crossover design is a variant of matched case-control study (Maclure 1991) and has been broadly adopted to investigate the associations of short-term environmental exposures with mortality and morbidity outcomes (Carracedo-Martinez et al. 2010). The unique advantages of case-control study include controlling the effects of day of week, season, and time-invariant confounders such as individual characteristics. In this study, case period was defined as the day of outpatient visit. Control periods were identified by matching the day of the week within the same year and month in order to eliminate the potential confounding effects of long-term trend.

\section{Statistical analyses}

Conditional logistic regression model was used to perform the analyses in our study. We estimated the odds ratios (ORs) and 95\% confidence intervals (CIs) of outpatient visits for respiratory diseases associated with a $10.0 \mu \mathrm{g} /$ $\mathrm{m}^{3}$ increase in daily concentrations of $\mathrm{NO}_{2}, \mathrm{SO}_{2}$, and $\mathrm{O}_{3}$, 
and a $1.0 \mathrm{mg} / \mathrm{m}^{3}$ increase in daily concentrations of CO. Since the effects of environmental risk factors are sometimes not observed instantly but are delayed, a lag analysis was conducted to observe the delayed effects of gaseous air pollutants on outpatient visits. For the lag analysis, we applied both single-day lag structures (lag0 to lag3) and multi-day lag structures (lag01 to lag03). For example, lag 1 corresponds to the air pollutant concentrations measured at 1 day prior to outpatient visit, while lag01 corresponds to the air pollutant concentrations averaged from current day's and lag1 day's measurements.

To adjust for nonlinear confounding effects of meteorological factors, we applied a restricted cubic spline (RCS) function with 3 degrees of freedom (df) for mean temperature, relative humidity, atmospheric pressure, and wind speed. Public holidays were controlled through the use of a binary variable (coded as public holiday $=1$ and no public holiday $=0$ ) in the model. All results were from models including mean temperature, relative humidity, atmospheric pressure, wind speed, and public holidays.

Because air pollutants possibly interact with each other and have a combined effect on health outcomes, we carried out analyses using multi-pollutant models. A principal component was introduced into the multi-pollutant models to obtain more reliable results without the impacts of collinearity between various air pollutants.

Subgroup analyses stratified by types of hospitals and departments (department of internal medicine in general hospitals, department of pediatrics in general hospitals, general outpatient in community hospitals), and the district where the hospital is located (Donghe District and Qingshan District). Sensitivity analyses were conducted to check the robustness of the results. First, we used $4 \mathrm{df}$ for all meteorological factors. Second, we excluded the data during the COVID-19 pandemic (data in 2020) for further analyses.

All analyses were conducted using R software (version 4.1.0). The "survival" package and "splines2" package were used for conditional logistic regression analysis. And "rms" package was used to fit the restricted cubic splines. All statistical tests were two-sided, and the statistical significance was defined as $p$ value less than 0.05 .

\section{Results}

\section{Descriptive statistics}

A total number of 168,201 patients visited the outpatient department for respiratory diseases in our participating hospitals between the years 2015 to 2020 . The mean number of daily outpatient visits was 76.7, including 31.0 for the department of internal medicine in general hospitals, 32.1 for the department of pediatrics in general hospitals, and 13.7 for the general outpatient in community hospitals (Table 1).

The daily average concentrations of air pollutants and meteorological variables in two districts between the years 2015 to 2020 are presented in Table 2. The means (standard deviation, SD) of air pollutants were $39.2(16.8) \mu \mathrm{g} / \mathrm{m}^{3}$ for $\mathrm{NO}_{2}, 26.7(18.3) \mu \mathrm{g} / \mathrm{m}^{3}$ for $\mathrm{SO}_{2}, 1.2(0.7) \mathrm{mg} / \mathrm{m}^{3}$ for $\mathrm{CO}$, and $93.8(41.7) \mu \mathrm{g} / \mathrm{m}^{3}$ for $\mathrm{O}_{3}$, respectively. Means (SD) of meteorological variables were $8.0(12.7){ }^{\circ} \mathrm{C}$ for temperature, 56.0 (16.4)\% for relative humidity, $902.3(6.9) \mathrm{kPa}$ for atmospheric pressure, and 2.9 (1.2) $\mathrm{m} / \mathrm{s}$ for wind speed. In Donghe District, the means (SD) of air pollutants were 38.8 (16.8) $\mu \mathrm{g} / \mathrm{m}^{3}$ for $\mathrm{NO}_{2}, 27.2(18.2) \mu \mathrm{g} / \mathrm{m}^{3}$ for $\mathrm{SO}_{2}, 1.2(0.7) \mathrm{mg} / \mathrm{m}^{3}$ for $\mathrm{CO}$, and $94.4(40.9) \mu \mathrm{g} / \mathrm{m}^{3}$ for $\mathrm{O}_{3}$, respectively. In Qingshan District, the means (SD) of air pollutants were 39.6 (16.9) $\mu \mathrm{g} / \mathrm{m}^{3}$ for $\mathrm{NO}_{2}, 26.2(18.4) \mu \mathrm{g} / \mathrm{m}^{3}$ for $\mathrm{SO}_{2}, 1.2(0.7)$ $\mathrm{mg} / \mathrm{m}^{3}$ for $\mathrm{CO}$, and 93.3 (42.6) $\mu \mathrm{g} / \mathrm{m}^{3}$ for $\mathrm{O}_{3}$, respectively.

\section{Correlation analyses}

Spearman correlation coefficients for correlations among the air pollutants and meteorological parameters are presented in Table 3. $\mathrm{NO}_{2}, \mathrm{SO}_{2}$, and $\mathrm{CO}$ showed positive correlations with each other $(r=0.79$ to $0.83, p<0.01)$ and particulate matter $(r=0.45$ to $0.62, p<0.01)$, and negative correlations with $\mathrm{O}_{3}(r=-0.52$ to $-0.39, p<0.01)$. Correlations were also observed between air pollutants and meteorological parameters. $\mathrm{NO}_{2}, \mathrm{SO}_{2}$, and $\mathrm{CO}$ were positively correlated with relative humidity ( $r=0.11$ to $0.36, p<0.01)$ and atmospheric pressure ( $r=0.24$ to $0.36, p<0.01)$, but negatively correlated with temperature $(r=-0.54$ to $-0.38, p<0.01)$ and wind speed $(r=-0.54$ to $-0.28, p<0.01)$. Conversely, $\mathrm{O}_{3}$ was positively correlated with temperature $(r=0.84$,
Table 1 Descriptive statistics of daily outpatient visits for respiratory diseases

\begin{tabular}{lccccccc}
\hline Variables & Mean & $\mathrm{SD}$ & $\mathrm{P}_{50}$ & $\mathrm{P}_{25}$ & $\mathrm{P}_{75}$ & Minimum & Maximum \\
\hline Total & 76.7 & 39.1 & 71.0 & 49.0 & 99.0 & 2.0 & 264.0 \\
Department of internal medicine & 31.0 & 20.8 & 30.0 & 14.0 & 44.0 & 0.0 & 117.0 \\
Department of pediatrics & 32.1 & 19.7 & 29.0 & 19.0 & 39.0 & 0.0 & 154.0 \\
General outpatient & 13.7 & 10.2 & 12.0 & 7.0 & 19.0 & 0.0 & 72.0 \\
\hline
\end{tabular}

$S D$ standard deviation, $P_{X \mathrm{X}}$ th percentiles 
Table 2 Summary statistics of daily air pollutants and meteorological parameters in Baotou
Table 3 Spearman correlation coefficients among the exposure variables

\begin{tabular}{|c|c|c|c|c|c|c|c|}
\hline Variables & Mean & SD & $\mathrm{P}_{50}$ & $\mathrm{P}_{25}$ & $\mathrm{P}_{75}$ & Minimum & Maximum \\
\hline \multicolumn{8}{|c|}{ Air pollutants concentrations ${ }^{a}$} \\
\hline \multicolumn{8}{|l|}{ Total } \\
\hline $\mathrm{NO}_{2}\left(\mu \mathrm{g} / \mathrm{m}^{3}\right)$ & 39.2 & 16.8 & 37.0 & 27.0 & 50.0 & 3.0 & 108.0 \\
\hline $\mathrm{SO}_{2}\left(\mu \mathrm{g} / \mathrm{m}^{3}\right)$ & 26.7 & 18.3 & 22.0 & 14.0 & 34.0 & 3.0 & 160.0 \\
\hline $\mathrm{CO}\left(\mathrm{mg} / \mathrm{m}^{3}\right)$ & 1.2 & 0.7 & 1.0 & 0.8 & 1.5 & 0.2 & 9.8 \\
\hline $\mathrm{O}_{3}\left(\mu \mathrm{g} / \mathrm{m}^{3}\right)$ & 93.8 & 41.7 & 90.0 & 62.0 & 122.0 & 7.0 & 233.0 \\
\hline \multicolumn{8}{|l|}{ Donghe District } \\
\hline $\mathrm{NO}_{2}\left(\mu \mathrm{g} / \mathrm{m}^{3}\right)$ & 38.8 & 16.8 & 36.0 & 26.0 & 49.0 & 7.0 & 108.0 \\
\hline $\mathrm{SO}_{2}\left(\mu \mathrm{g} / \mathrm{m}^{3}\right)$ & 27.2 & 18.2 & 22.0 & 14.0 & 35.0 & 3.0 & 160.0 \\
\hline $\mathrm{CO}\left(\mathrm{mg} / \mathrm{m}^{3}\right)$ & 1.2 & 0.7 & 1.0 & 0.8 & 1.5 & 0.2 & 5.4 \\
\hline $\mathrm{O}_{3}\left(\mu \mathrm{g} / \mathrm{m}^{3}\right)$ & 94.4 & 40.9 & 91.0 & 63.0 & 123.0 & 7.0 & 233.0 \\
\hline \multicolumn{8}{|l|}{ Qingshan District } \\
\hline $\mathrm{NO}_{2}\left(\mu \mathrm{g} / \mathrm{m}^{3}\right)$ & 39.6 & 16.9 & 38.0 & 27.0 & 50.0 & 3.0 & 107.0 \\
\hline $\mathrm{SO}_{2}\left(\mu \mathrm{g} / \mathrm{m}^{3}\right)$ & 26.2 & 18.4 & 21.0 & 13.0 & 33.0 & 3.0 & 156.0 \\
\hline $\mathrm{CO}\left(\mathrm{mg} / \mathrm{m}^{3}\right)$ & 1.2 & 0.7 & 1.0 & 0.7 & 1.4 & 0.2 & 9.8 \\
\hline $\mathrm{O}_{3}\left(\mu \mathrm{g} / \mathrm{m}^{3}\right)$ & 93.3 & 42.6 & 89.0 & 61.0 & 122.0 & 8.0 & 232.0 \\
\hline \multicolumn{8}{|l|}{ Meteorological parameters } \\
\hline Temperature $\left({ }^{\circ} \mathrm{C}\right)$ & 8.0 & 12.7 & 9.7 & -3.7 & 19.6 & -20.6 & 30.1 \\
\hline Relative humidity (\%) & 56.0 & 16.4 & 57.0 & 44.0 & 67.0 & 12.0 & 97.0 \\
\hline Atmospheric pressure $(\mathrm{kPa})$ & 902.3 & 6.9 & 902.3 & 896.3 & 907.5 & 885.0 & 924.7 \\
\hline Wind speed $(\mathrm{m} / \mathrm{s})$ & 2.9 & 1.2 & 2.7 & 2.1 & 3.6 & 0.4 & 10.5 \\
\hline
\end{tabular}

a24-h averages for $\mathrm{NO}_{2}, \mathrm{SO}_{2}$, and $\mathrm{CO}$; the maximal 8-h average for $\mathrm{O}_{3}$ $S D$ standard deviation, $P_{X}$ th percentiles

\begin{tabular}{lllllllllll}
\hline Variables & $\mathrm{NO}_{2}$ & $\mathrm{SO}_{2}$ & $\mathrm{CO}$ & $\mathrm{O}_{3}$ & $\mathrm{PM}_{10}$ & $\mathrm{PM}_{2.5}$ & $\mathrm{Temp}$ & $\mathrm{RH}$ & $\mathrm{AP}$ & $\mathrm{WS}$ \\
\hline $\mathrm{NO}_{2}$ & 1.00 & $0.79^{* *}$ & $0.83^{* *}$ & $-0.39^{* *}$ & $0.57^{* *}$ & $0.51^{* *}$ & $-0.38^{* *}$ & $0.24^{* *}$ & $0.24^{* *}$ & $-0.54^{* *}$ \\
$\mathrm{SO}_{2}$ & - & 1.00 & $0.81^{* *}$ & $-0.47^{* *}$ & $0.62^{* *}$ & $0.46^{* *}$ & $-0.52^{* *}$ & $0.11^{* *}$ & $0.33^{* *}$ & $-0.28^{* *}$ \\
$\mathrm{CO}$ & - & - & 1.00 & $-0.52^{* *}$ & $0.51^{* *}$ & $0.45^{* *}$ & $-0.54^{* *}$ & $0.36^{* *}$ & $0.36^{* *}$ & $-0.43^{* *}$ \\
$\mathrm{O}_{3}$ & - & - & - & 1.00 & $-0.23^{* *}$ & $0.21^{* *}$ & $0.84^{* *}$ & $-0.21^{* *}$ & $-0.71^{* *}$ & $0.19^{* *}$ \\
$\mathrm{PM}_{10}$ & - & - & - & - & 1.00 & $0.71^{* *}$ & $-0.25^{* *}$ & $-0.09^{* *}$ & 0.02 & -0.04 \\
$\mathrm{PM}_{2.5}$ & - & - & - & - & - & 1.00 & $0.12^{* *}$ & $0.15^{* *}$ & $-0.28^{* *}$ & $-0.13^{* *}$ \\
$\mathrm{Temp}$ & - & - & - & - & - & - & 1.00 & $-0.07^{* *}$ & $-0.81^{* *}$ & $0.17^{* *}$ \\
$\mathrm{RH}$ & - & - & - & - & - & - & - & 1.00 & $0.05^{*}$ & $-0.24^{* *}$ \\
$\mathrm{AP}$ & - & - & - & - & - & - & - & - & 1.00 & $-0.19^{* *}$ \\
$\mathrm{WS}$ & - & - & - & - & - & - & - & - & - & 1.00 \\
\hline
\end{tabular}

Temp temperature, $R H$ relative humidity, $A P$ atmospheric pressure, $W S$ wind speed. ${ }^{*} p<0.05,{ }^{* *} p<0.01$ $p<0.01)$ and wind speed $(r=0.19, p<0.01)$, while negatively correlated with relative humidity $(r=-0.21, p<0.01)$ and atmospheric pressure $(r=-0.71, p<0.01)$.

\section{General analyses}

Table 4 shows the ORs (95\% CI) of outpatient visits for total respiratory diseases at various exposure days associated with per $10 \mu \mathrm{g} / \mathrm{m}^{3}$ increase in exposure to $\mathrm{NO}_{2}, \mathrm{SO}_{2}$, and $\mathrm{O}_{3}$, and per $1 \mathrm{mg} / \mathrm{m}^{3}$ increases in exposure to $\mathrm{CO}$. Positive results were observed for $\mathrm{NO}_{2}$ among all lag structures, for $\mathrm{SO}_{2}$ at lag1-3 and lag02-03, and for CO at lag0-2 and lag01-03, where the highest was at $\operatorname{lag} 0, \operatorname{lag} 03$, and $\operatorname{lag} 01$ respectively. Negative results were observed for $\mathrm{O}_{3}$ at lag1 and lag01-02.

\section{Stratification analyses}

Figure 1 summarizes the subgroup of different departments' analyses results for lag days of 0-3 and 01-03. We found $\mathrm{NO}_{2}$ was associated with outpatient visits for respiratory diseases in all subgroups and were associated most strongly among children $(\mathrm{OR}=1.005$ to 1.027$) . \mathrm{SO}_{2}$ 
Table 4 ORs $(95 \% \mathrm{CI})$ for outpatient visits for respiratory diseases associated with exposure to air pollutants

\begin{tabular}{lllll}
\hline Lag & \multicolumn{2}{l}{ Variables } & & \\
\cline { 2 - 5 } & $\mathrm{NO}_{2}$ & $\mathrm{SO}_{2}$ & $\mathrm{CO}$ & $\mathrm{O}_{3}$ \\
\hline 0 & $1.033(1.018,1.049)^{* *}$ & $0.965(0.954,0.976)^{* *}$ & $1.038(1.006,1.072)^{*}$ & $0.996(0.990,1.003)$ \\
1 & $1.015(1.010,1.020)^{* *}$ & $1.008(1.003,1.013)^{* *}$ & $1.034(1.022,1.048)^{* *}$ & $0.996(0.993,0.999)^{*}$ \\
2 & $1.008(1.004,1.012)^{* *}$ & $1.005(1.001,1.010)^{*}$ & $1.014(1.002,1.025)^{*}$ & $1.000(0.997,1.003)$ \\
3 & $1.006(1.002,1.010)^{* *}$ & $1.006(1.001,1.010)^{*}$ & $1.009(0.998,1.020)$ & $1.002(0.999,1.004)$ \\
01 & $1.021(1.014,1.028)^{* *}$ & $1.003(0.995,1.011)$ & $1.047(1.027,1.067)^{* *}$ & $0.995(0.991,0.998)^{* *}$ \\
02 & $1.023(1.016,1.031)^{* *}$ & $1.009(1.000,1.018)^{*}$ & $1.046(1.026,1.066)^{* *}$ & $0.995(0.991,1.000)^{*}$ \\
03 & $1.025(1.018,1.033)^{* *}$ & $1.014(1.005,1.023)^{* *}$ & $1.045(1.024,1.066)^{* *}$ & $0.997(0.993,1.002)$ \\
\hline
\end{tabular}

${ }^{*} p<0.05,{ }^{* *} p<0.01$
Fig. 1 Summary of stratified analyses results by hospital departments for different lag structures
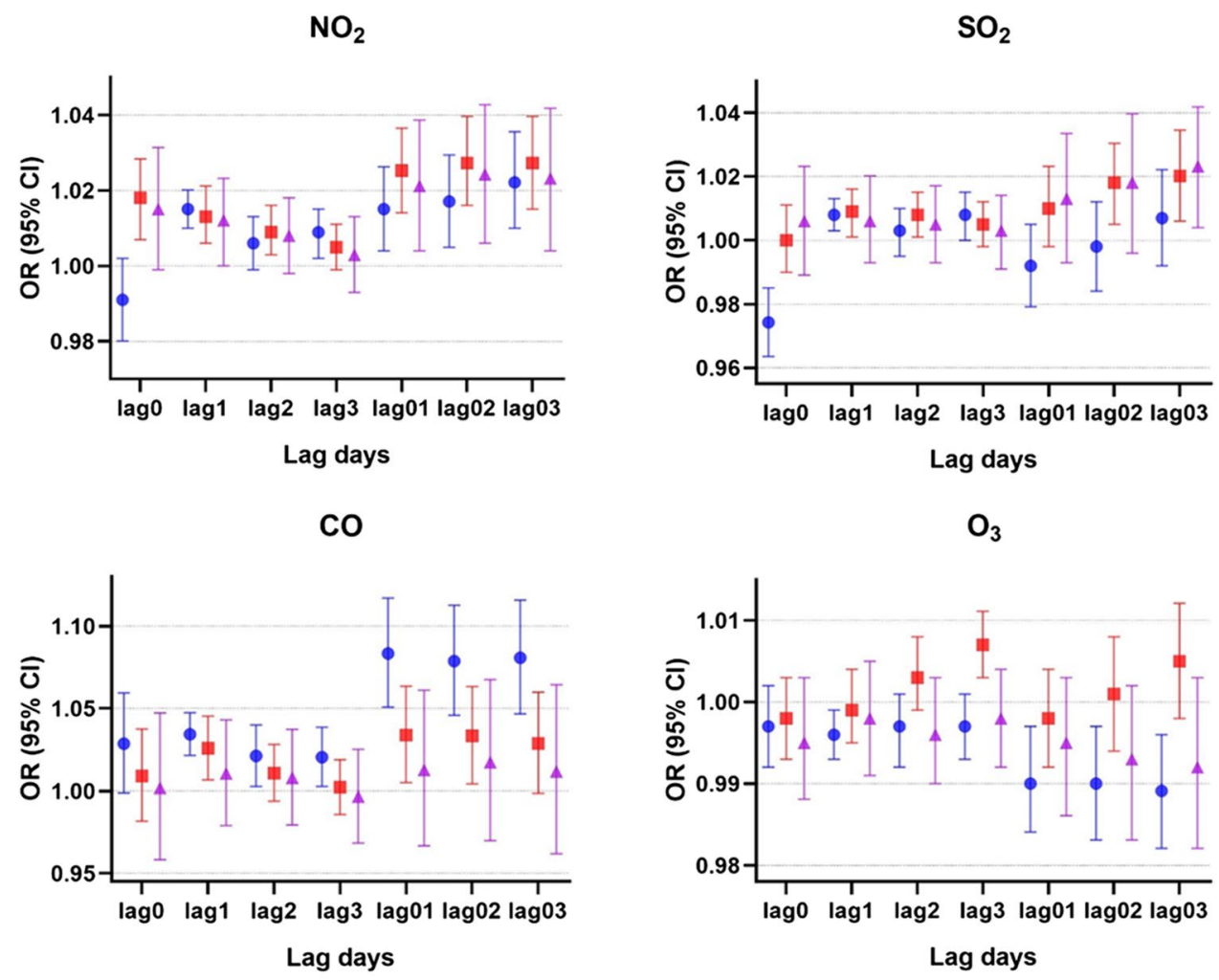

- Department of internal medicine in general hospitals

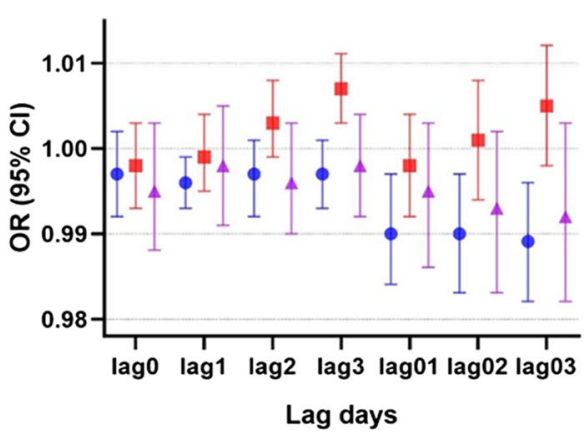

Department of pediatrics in General outpatient in general hospitals was found associated with outpatient visits for respiratory diseases in department of internal medicine in general hospitals at lag 1 and lag 3 , in department of pediatrics in general hospitals at lag1-2 and lag02-03, and in general outpatient in community hospitals at lag3. CO was found associated with outpatient visits for respiratory diseases in department of internal medicine in general hospitals at lag1-3 and lag01-03 and in department of pediatrics in general hospitals at lag1 and lag01-02. Unlike other gaseous pollutants, $\mathrm{O}_{3}$ was found negatively associated with outpatient visits in department of internal medicine in general hospitals at lag1 and lag01-03.
Figure 2 summarizes the subgroup of different districts' analyses results for lag days of $0-3$ and $01-03$. $\mathrm{NO}_{2}$ was found more associated with outpatient visits for respiratory diseases in Qingshan District, which had larger ORs and narrower confidence intervals. $\mathrm{SO}_{2}$ and $\mathrm{CO}$ were found more associated with outpatient visits for respiratory diseases in Donghe District. Also, $\mathrm{O}_{3}$ were found negatively associated with outpatient visits in Qingshan District in most lag structures. 
Fig. 2 Summary of stratified analyses results by districts for different lag structures

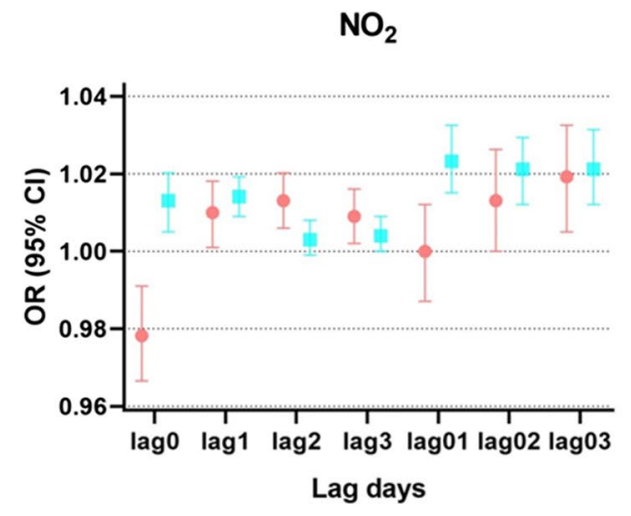

co

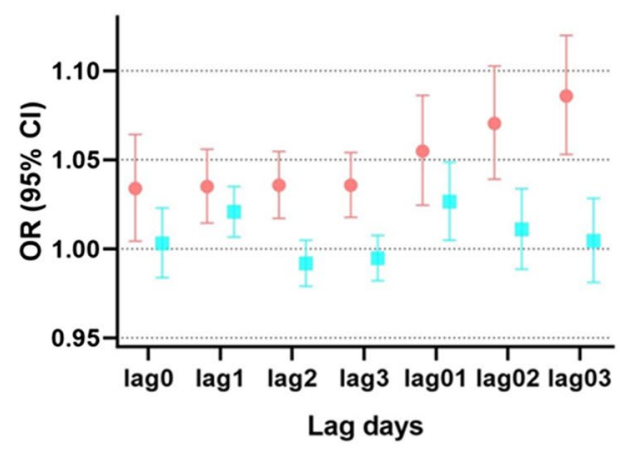

- Donghe District

Fig. 3 Exposure-response relationships of outpatient visits for respiratory diseases with 4-day moving average concentrations of air pollutants in different pollutant models
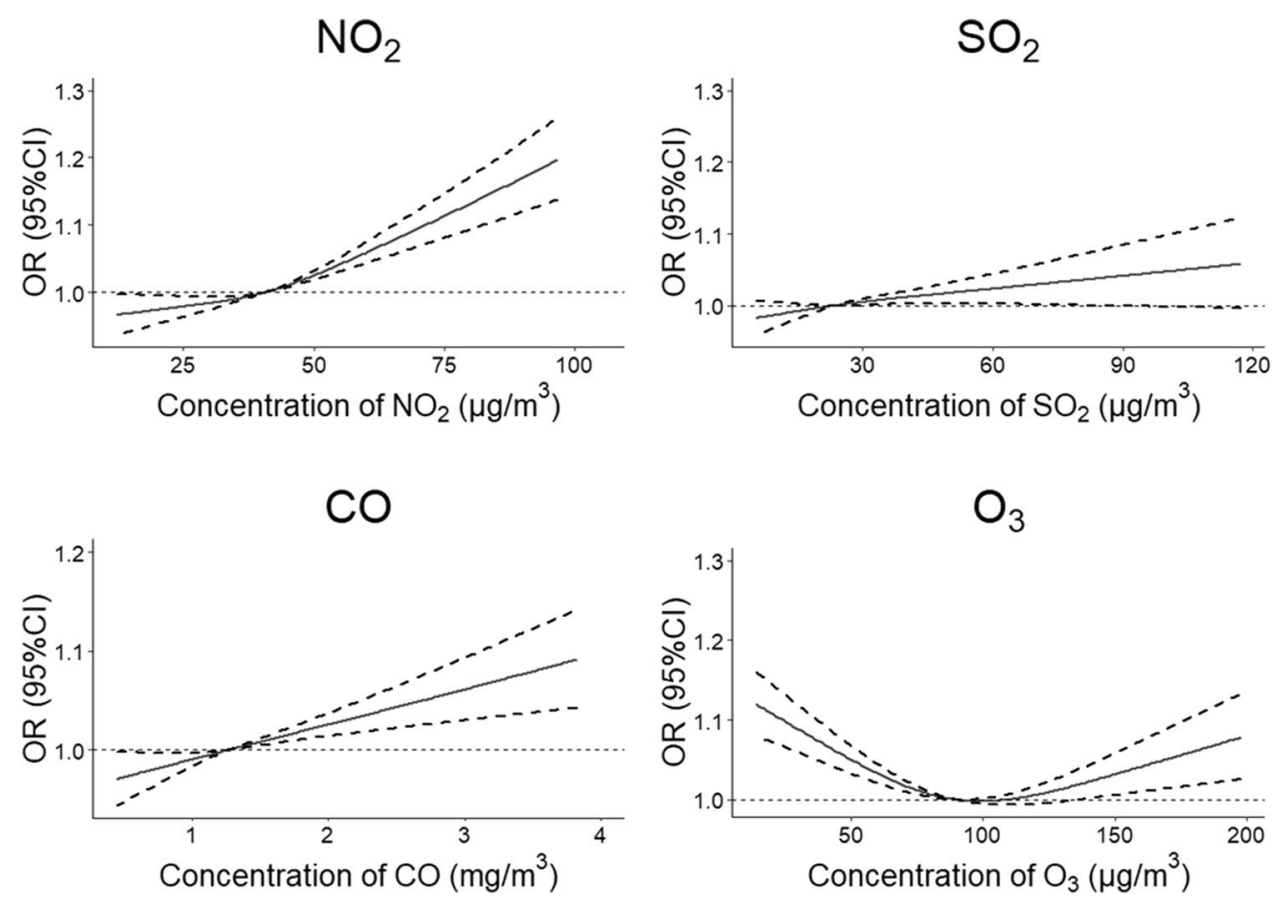

$\mathrm{SO}_{2}$

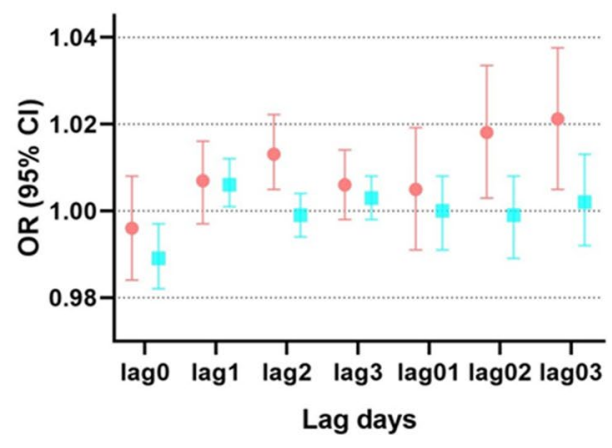

$\mathrm{O}_{3}$

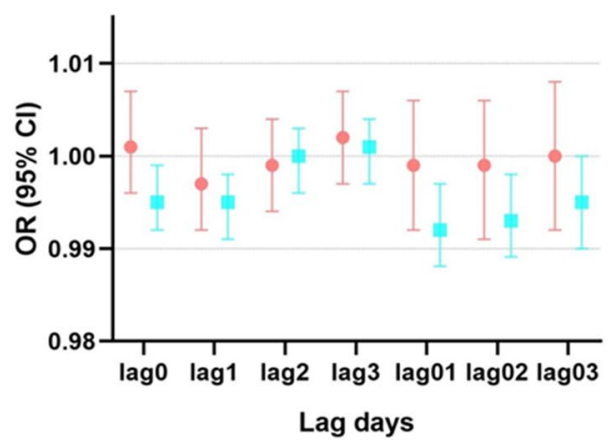

Ininghan District 


\section{Exposure-response analyses}

Figure 3 shows the exposure-response relationships of outpatient visits for respiratory diseases with 4-day (lag0-3) moving average concentrations of $\mathrm{NO}_{2}, \mathrm{SO}_{2}, \mathrm{CO}$, and $\mathrm{O}_{3}$ in different pollutant models. The exposure-response curves suggested an approximately linear increase in outpatient visits risks with daily changes in $\mathrm{NO}_{2}, \mathrm{SO}_{2}$, and $\mathrm{CO}$ in both single-pollutant models and multi-pollutant models. For $\mathrm{O}_{3}$, there was a linear increase in outpatient visits risks at higher $\mathrm{O}_{3}$ concentrations, with a threshold of around $89 \mu \mathrm{g} / \mathrm{m}^{3}$ for a 8 -h average exposure.
Fig. 4 The association between air pollutants' concentrations and outpatient visits for respiratory diseases by adjusting the $\mathrm{df}$ (s) of meteorological factors
Fig. 5 The association between air pollutants' concentrations and outpatient visits for respiratory diseases in Baotou, from 2015 to 2019
$\mathrm{NO}_{2}$

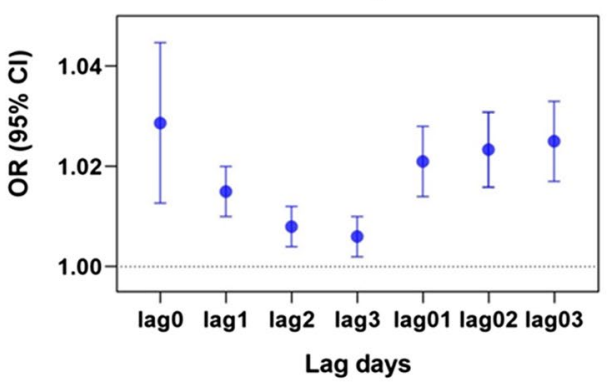

CO

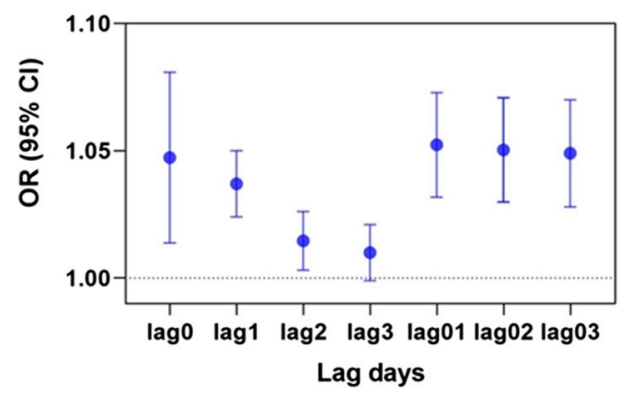

$\mathrm{NO}_{2}$

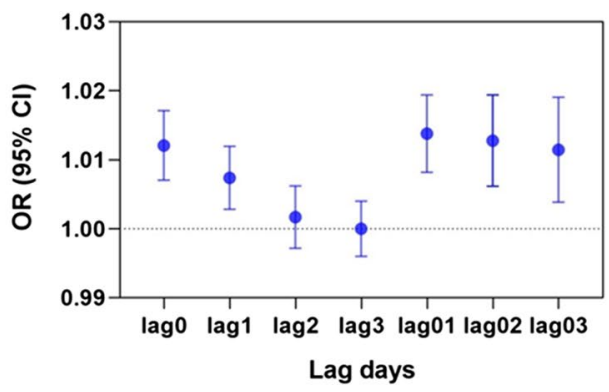

CO

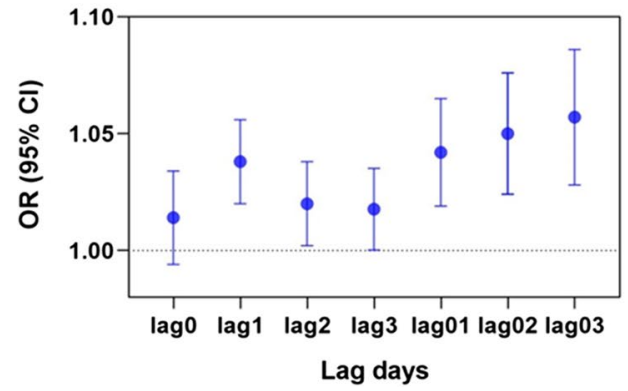

$\mathrm{SO}_{2}$

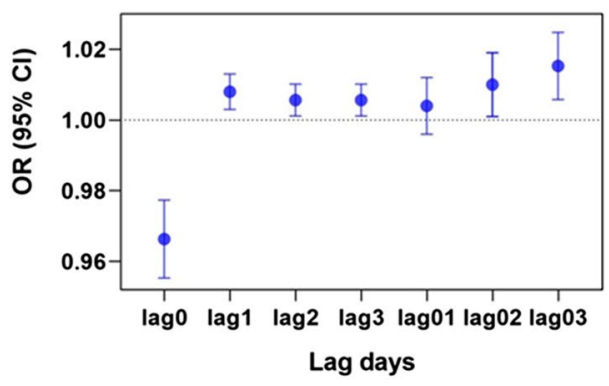

$\mathrm{O}_{3}$

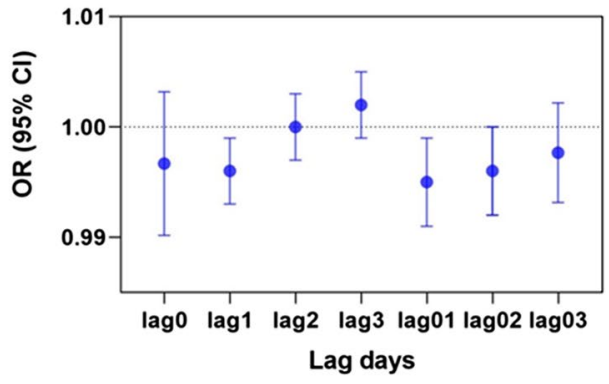

$\mathrm{SO}_{2}$

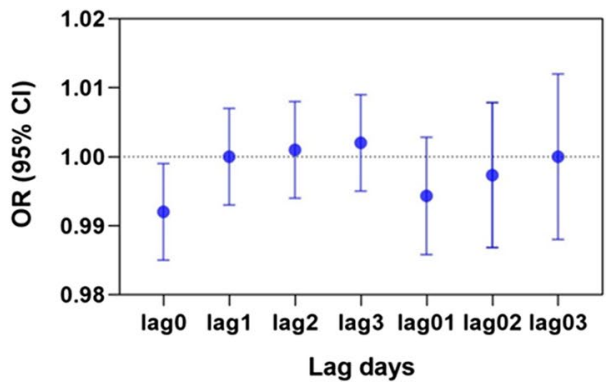

$\mathrm{O}_{3}$

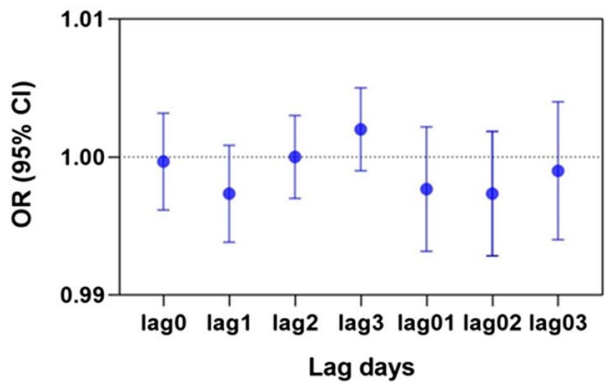




\section{Sensitivity analyses}

The results of sensitivity analyses are shown in Fig. 4 and Fig. 5. The main findings of our study did not change after adjusting the degrees of freedom of temperature, relative humidity, atmospheric pressure, and wind speed. The effects of $\mathrm{SO}_{2}$ on outpatient visits for respiratory diseases decreased after excluding the data in 2020.

\section{Discussion}

In this time-stratified case-crossover study, exposures to $\mathrm{NO}_{2}, \mathrm{SO}_{2}$, and $\mathrm{CO}$ were found positively associated with outpatient visits for respiratory diseases. Besides, an approximately linear exposure-response relationship of outpatient visits for respiratory diseases at higher $\mathrm{O}_{3}$ levels was observed. Short-term effects of gaseous air pollutants on outpatient visits for respiratory diseases varied slightly among different departments and districts.

Globally, air pollution has become a serious public health concern (Chen et al. 2020), and various epidemiological studies report that short-term exposure to air pollutants may cause adverse health effects (Guan et al. 2016). Our results suggested an approximately linear exposure-response relationship of respiratory diseases with short-term $\mathrm{NO}_{2}, \mathrm{SO}_{2}$, and $\mathrm{CO}$ exposures, and they were positively associated with outpatient visits for respiratory diseases. These results were consistent with the previous findings worldwide, in spite of heterogeneity in effect estimates across various regions of the world (Liu et al. 2017; Tramuto et al. 2011; Yang et al. 2021). Evidence of the effect of air pollutants on respiratory health has been accumulating (Dockery et al. 2013). Putative biological mechanisms linking air pollution to respiratory diseases involve direct effect of air pollutants on the lung and indirect effects that mediated by oxidative stress and pulmonary inflammation (Zhang et al. 2019b).

Other studies have shown that meteorological factors have an effect on the concentrations of air pollutants, which is similar with some other studies ( $\mathrm{Li}$ et al. 2019; Zhang et al. 2015). The concentration of $\mathrm{O}_{3}$ had a positive association with temperature and a negative association with relative humidity, because sunshine can promote the production process of $\mathrm{O}_{3}$, and relative humidity might have negative effects on sunshine duration (Jiang et al. 2020). The concentrations of $\mathrm{NO}_{2}, \mathrm{SO}_{2}$, and $\mathrm{CO}$ were negatively correlated with wind speed and temperature, indicating that horizontal dispersion plays an important role in modulating air pollutants concentration (Zhang et al. 2015). In China, low temperature might promote coal burning and heating, and thus, low temperature has a negative impact on air pollutants concentrations (Wang et al. 2019). In view of the fact that meteorological factors can influence air pollutants, thereby impacting health, we introduced meteorological factors into each models.

In comparison to studies carried out in other cities, results of this study had similar trends. A study done in Fuzhou, China, associated exposure to $\mathrm{NO}_{2}$ and outpatient visits for respiratory diseases with estimated OR of 1.051 (95\% CI: 1.031 to 1.070 ) (Jiang et al. 2020), while ours was 1.033 (95\% CI: 1.018 to 1.049). Another study in Southeastern China associated exposure to $\mathrm{SO}_{2}$ and outpatient visits for respiratory diseases with estimated relative risk of 1.035 (95\% CI: 1.029 to 1.041 ) at lag1 (Mo et al. 2018), while our OR was 1.008 (95\% CI: 1.003 to 1.013). At the same time, our results showed that, although $\mathrm{SO}_{2}$ was positively correlated with outpatient visits for respiratory diseases in several lag structures, they were negatively related to each other at lag0. Similar results to ours have been reported in other studies (Dong et al. 2021), and one of the possible reasons is that irritating gaseous air pollutants including $\mathrm{SO}_{2}$ can cause inflammation in the respiratory tract after several days (Chang et al. 2020). Quite a few studies stated that the effect of $\mathrm{CO}$ on respiratory diseases was positive and has statistically significant effect (Chang et al. 2020); we also obtained the same result (OR $=1.038,95 \% \mathrm{CI}: 1.006$ to 1.072). Unlike other gaseous air pollutants, we found $\mathrm{O}_{3}$ was negatively correlated with outpatient visits for respiratory diseases at low concentration while positively correlated with that at high concentration. This might be due to the negative association between $\mathrm{O}_{3}$ and other gaseous air pollutants, which were more strongly associated with respiratory diseases. Meanwhile, high concentration of $\mathrm{O}_{3}$ led to bronchial inflammation and hyper-responsiveness, and this further led to respiratory diseases (Kim et al. 2020).

Single-day lag structures ( $\operatorname{lag} 0-3)$ and multi-day lag structures (lag01-03) were adopted in our study to investigate the lag relationship of gaseous air pollutants and outpatient visits for respiratory diseases. The effect estimates of multi-day lag structures were slightly larger and more stable than those of single-day lag structures for all four gaseous air pollutants. These findings are consistent with some other studies, which suggest that accumulated exposure of air pollutants increases the risk of respiratory diseases (Lin et al. 2017; Mokoena et al. 2019). We also observed that the OR value of $\mathrm{SO}_{2}$ was largest at lag2, while the $\mathrm{OR}$ values of $\mathrm{NO}_{2}$ and $\mathrm{CO}$ were largest at lag0.

The subgroup analyses showed that the positive associations of outpatient visits for respiratory diseases with $\mathrm{NO}_{2}$ and $\mathrm{O}_{3}$ appear to be stronger among children, and these were in accordance with previous studies (Mo et al. 2018). These may suggest that children will be more sensitive than adults to air pollutants due to their narrower airways, developing lung functions, immature immune system, and longer staytime outdoors (Yang et al. 2021). Additionally, some multicity studies in China reported that stronger associations 
between air pollutants and respiratory diseases among areas with lowest air pollutants concentrations (Tian et al. 2019; Yang et al. 2021; Zhu et al. 2017). However, we did not find this trend in this study. As shown in Table 2, the average concentrations of $\mathrm{SO}_{2}$ and $\mathrm{CO}$ in Donghe District were higher than those in Qingshan District. Contrary to expectations, these two kinds of gaseous pollutants were found more associated with outpatient visits for respiratory diseases in Donghe District. These inconsistent results could be attributed to differences in both location and patient composition between hospitals in different districts.

Results from sensitivity analyses by adjusting the degrees of freedom of meteorological parameters were essentially unchanged from primary analyses. After excluding the data in 2020, we found that effects of $\mathrm{SO}_{2}$ on outpatient visits for respiratory diseases decreased. This may be attributed that more attention has been given to respiratory symptoms during the COVID-19 pandemic. And people are more willing to go to the hospital seeking treatment when they experience respiratory symptoms.

\section{Strengths and limitations}

There are several strengths of this study. The time-stratified case-crossover design using in our study could effectively control for confounding due to individual-level characteristics. Moreover, respiratory diseases in our study were diagnosed and classified based on ICD-10 code in order to eliminate the possibility misclassification of cases.

We are aware of some limitations of our study. Air pollutant data in our study were based on district-wide averages rather than personal exposure measurements. In addition, the concentrations of air pollutants were collected on the day that patients visited the hospital not on the day of the onset of disease. Besides, we could not do subgroup analysis in different age groups and in subgroups of ICD-10, and analyze the differences in patient populations between four hospitals because these data are unavailable. These limitations might affect the results of our study to a certain extent.

\section{Conclusions}

$\mathrm{NO}_{2}, \mathrm{SO}_{2}$, and $\mathrm{CO}$ were positively associated with outpatient visits for respiratory diseases. Stronger associations between them were among children. An approximately linear exposure-response relationship of outpatient visits for respiratory diseases with $\mathrm{O}_{3}$ was observed at higher $\mathrm{O}_{3}$ concentrations, with a threshold of around $89 \mu \mathrm{g} / \mathrm{m}^{3}$ for an 8-h average exposure.
Acknowledgements We sincerely thank Baotou Center for Disease Control and Prevention for data collection and management.

Author contribution Hao-Yu Gao performed data analysis and drafted the manuscript. Xiao-Ling Liu participated in the data collection. Ya-Ke Lu and Yu-Hong Liu participated in the data cleaning. Li-Kun $\mathrm{Hu}$ and Yan-Ling Li participated in data analysis. Xiao-Dong Feng and Yu-Xiang Yan developed the study design and edited the manuscript. All authors read and approved the final version of the manuscript.

Data availability The data that support the findings of this study are available from the Baotou Center for Disease Control and Prevention, but restrictions apply to the availability of these data, which were used under license for the current study, and so are not publicly available. Data are however available from the authors upon reasonable request and with permission of Baotou Center for Disease Control and Prevention.

\section{Declarations}

Ethics approval and consent to participate Not applicable.

Consent for publication Not applicable.

Competing interest The authors declare no conflict of interest.

\section{References}

Amann M, Kiesewetter G, Schopp W, Klimont Z, Winiwarter W, Cofala J, Rafaj P, Hoglund-Isaksson L, Gomez-Sabriana A, Heyes C, Purohit P, Borken-Kleefeld J, Wagner F, Sander R, Fagerli H, Nyiri A, Cozzi L, Pavarini C (2020) Reducing global air pollution: the scope for further policy interventions. Philos Trans A Math Phys Eng Sci 378:20190331

Bao Y, Xu Y, Qi L, Zhai S (2020) Modeling the influence of nonclinic visits on the transmission of respiratory diseases. Comput Math Methods Med 2020:8049631

Carracedo-Martinez E, Taracido M, Tobias A, Saez M, Figueiras A (2010) Case-crossover analysis of air pollution health effects: a systematic review of methodology and application. Environ Health Perspect 118:1173-1182

Chang Q, Zhang H, Zhao Y (2020) Ambient air pollution and daily hospital admissions for respiratory system-related diseases in a heavy polluted city in Northeast China. Environ Sci Pollut Res Int 27:10055-10064

Chen YW, Huang MZ, Chen CL, Kuo CY, Yang CY, Chiang-Ni C, Chen YM, Hsieh CM, Wu HY, Kuo ML, Chiu CH, Lai CH (2020) PM2.5 impairs macrophage functions to exacerbate pneumococcus-induced pulmonary pathogenesis. Part Fibre Toxicol 17:37

Chen T, Chen F, Wang K, Ma X, Wei X, Wang W, Huang P, Yang D, Xia Z, Zhao Z (2021) Acute respiratory response to individual particle exposure (PM(1.0), $\mathrm{PM}(2.5)$ and $\mathrm{PM}(10))$ in the elderly with and without chronic respiratory diseases. Environ Pollut 271:116329

Cohen AJ et al (2017) Estimates and 25-year trends of the global burden of disease attributable to ambient air pollution: an analysis of data from the Global Burden of Diseases Study 2015. The Lancet 389:1907-1918

Dockery DW, Rich DQ, Goodman PG, Clancy L, Ohman-Strickland P, George P, Kotlov T (2013): Effect of air pollution control on mortality and hospital admissions in Ireland. Res Rep Health Eff Inst, 3-109 
Dong J, Liu Y, Bao H (2021) Revalue associations of short-term exposure to air pollution with respiratory hospital admissions in Lanzhou, China after the control and treatment of current pollution. Int J Hyg Environ Health 231:113658

Guan W-J, Zheng X-Y, Chung KF, Zhong N-S (2016) Impact of air pollution on the burden of chronic respiratory diseases in China: time for urgent action. The Lancet 388:1939-1951

Jiang Y, Chen J, Wu C, Lin X, Zhou Q, Ji S, Yang S, Zhang X, Liu B (2020) Temporal cross-correlations between air pollutants and outpatient visits for respiratory and circulatory system diseases in Fuzhou. China BMC Public Health 20:1131

Katsouyanni K, Touloumi G, Spix C, Schwartz J, Balducci F, Medina S, Rossi G, Wojtyniak B, Sunyer J, Bacharova L, Schouten JP, Ponka A, Anderson HR (1997) Short-term effects of ambient sulphur dioxide and particulate matter on mortality in 12 European cities: results from time series data from the APHEA project. Air Pollution and Health: a European Approach. BMJ 314:1658-1663

Kim SY, Kim E, Kim WJ (2020) Health effects of ozone on respiratory diseases. Tuberc Respir Dis (seoul) 83:S6-S11

Li R, Wang Z, Cui L, Fu H, Zhang L, Kong L, Chen W, Chen J (2019) Air pollution characteristics in China during 2015-2016: spatiotemporal variations and key meteorological factors. Sci Total Environ 648:902-915

Lin H, Ratnapradipa K, Wang X, Zhang Y, Xu Y, Yao Z, Dong G, Liu T, Clark J, Dick R, Xiao J, Zeng W, Li X, Qian Z, Ma W (2017) Hourly peak concentration measuring the PM 2.5 -mortality association: results from six cities in the Pearl River Delta study. Atmos Environ 161:27-33

Liu Y, Xie S, Yu Q, Huo X, Ming X, Wang J, Zhou Y, Peng Z, Zhang H, Cui X, Xiang H, Huang X, Zhou T, Chen W, Shi T (2017) Short-term effects of ambient air pollution on pediatric outpatient visits for respiratory diseases in Yichang city, China. Environ Pollut 227:116-124

Loomis D, Grosse Y, Lauby-Secretan B, El Ghissassi F, Bouvard V, Benbrahim-Tallaa L, Guha N, Baan R, Mattock H, Straif K (2013) The carcinogenicity of outdoor air pollution. Lancet Oncol $14: 1262-1263$

Maclure M (1991) The case-crossover design: a method for studying transient effects on the risk of acute events. Am J Epidemiol 133:144-153

Mo Z, Fu Q, Zhang L, Lyu D, Mao G, Wu L, Xu P, Wang Z, Pan X, Chen Z, Wang X, Lou X (2018) Acute effects of air pollution on respiratory disease mortalities and outpatients in Southeastern China. Sci Rep 8:3461

Ministry of Ecology and Environment of the People's Republic of China. Brief introduction of national ecological environment quality in 2019. 2020. http://www.mee.gov.cn/xxgk2018/xxgk/ xxgk15/202005/t20200507_777895.html. Accessed 2020-05-07

Mokoena KK, Ethan CJ, Yu Y, Shale K, Liu F (2019) Ambient air pollution and respiratory mortality in Xi' an, China: a time-series analysis. Respir Res 20:139

Nwanaji-Enwerem JC, Colicino E, Trevisi L, Kloog I, Just AC, Shen J, Brennan K, Dereix A, Hou L, Vokonas P, Schwartz J, Baccarelli AA (2016): Long-term ambient particle exposures and blood DNA methylation age: findings from the VA normative aging study. Environ Epigenet 2
Phung D, Hien TT, Linh HN, Luong LM, Morawska L, Chu C, Binh ND, Thai PK (2016) Air pollution and risk of respiratory and cardiovascular hospitalizations in the most populous city in Vietnam. Sci Total Environ 557-558:322-330

Soriano JB et al (2020) Prevalence and attributable health burden of chronic respiratory diseases, 1990-2017: a systematic analysis for the Global Burden of Disease Study 2017. Lancet Respir Med 8:585-596

Tian Y, Liu H, Liang T, Xiang X, Li M, Juan J, Song J, Cao Y, Wang X, Chen L, Wei C, Gao P, Hu Y (2019) Fine particulate air pollution and adult hospital admissions in 200 Chinese cities: a time-series analysis. Int J Epidemiol 48:1142-1151

Tramuto F, Cusimano R, Cerame G, Vultaggio M, Calamusa G, Maida CM, Vitale F (2011) Urban air pollution and emergency room admissions for respiratory symptoms: a case-crossover study in Palermo. Italy Environ Health 10:31

Wang S, Li Y, Niu A, Liu Y, Su L, Song W, Liu J, Liu Y, Li H (2018) The impact of outdoor air pollutants on outpatient visits for respiratory diseases during 2012-2016 in Jinan. China Respir Res $19: 246$

Wang H, Liu G, Shi K (2019) What Are the Driving Forces of Urban $\mathrm{CO} 2$ Emissions in China? Int J Environ Res Public Health, A refined scale analysis between national and urban agglomeration levels, p 16

Yang H, Yan C, Li M, Zhao L, Long Z, Fan Y, Zhang Z, Chen R, Huang Y, Lu C, Zhang J, Tang J, Liu H, Liu M, Guo W, Yang L, Zhang X (2021) Short term effects of air pollutants on hospital admissions for respiratory diseases among children: a multi-city time-series study in China. Int J Hyg Environ Health 231:113638

Zhang H, Wang Y, Hu J, Ying Q, Hu XM (2015) Relationships between meteorological parameters and criteria air pollutants in three megacities in China. Environ Res 140:242-254

Zhang Z, Chai P, Wang J, Ye Z, Shen P, Lu H, Jin M, Gu M, Li D, Lin $\mathrm{H}$, Chen K (2019) Association of particulate matter air pollution and hospital visits for respiratory diseases: a time-series study from China. Environ Sci Pollut Res Int 26:12280-12287

Zhang Z, Wang J, Liu F, Yuan L, Yuan J, Chen L, Zhong N, Lu W (2019) Impacts of event-specific air quality improvements on total hospital admissions and reduced systemic inflammation in COPD patients. PLoS One 14:e0208687

Zhang Y, Ding Z, Xiang Q, Wang W, Huang L, Mao F (2020) Shortterm effects of ambient PM1 and PM2.5 air pollution on hospital admission for respiratory diseases: Case-crossover evidence from Shenzhen, China. Int J Hyg Environ Health 224:113418

Zhu L, Ge X, Chen Y, Zeng X, Pan W, Zhang X, Ben S, Yuan Q, Xin J, Shao W, Ge Y, Wu D, Han Z, Zhang Z, Chu H, Wang M (2017) Short-term effects of ambient air pollution and childhood lower respiratory diseases. Sci Rep 7:4414

Publisher's note Springer Nature remains neutral with regard to jurisdictional claims in published maps and institutional affiliations. 